\title{
Different doses of tenecteplase vs alteplase in thrombolysis therapy of acute ischemic stroke: evidence from randomized controlled trials
}

This article was published in the following Dove Press journal:

Drug Design, Development and Therapy

\author{
$\mathrm{Na} \mathrm{Xu}^{1,2, *}$ \\ Zhouqing Chen ${ }^{1, *}$ \\ Chongshun Zhao' \\ Tao Xue' \\ Xin Wu' \\ Xiaoou Sun' \\ Zhong Wang'
}

'Department of Neurosurgery \& Brain and Nerve Research Laboratory, The First Affiliated Hospital of Soochow University, Suzhou, People's Republic of China; ${ }^{2}$ State Key Laboratory of Medical Neurobiology, Institute of Brain Sciences and Collaborative Innovation Center for Brain Science, Fudan University, Shanghai, People's Republic of China

*These authors contributed equally to this work
Correspondence: Zhong Wang;

Xiaoou Sun

Department of Neurosurgery \& Brain and Nerve Research Laboratory, The First Affiliated Hospital of Soochow University, 188 Shizi Street, Suzhou, Jiangsu Province 215006, People's Republic of China Email wangzhong76I@I63.com; sunxo76@163.com
Background: Recent studies showed inconsistent results of tenecteplase vs alteplase for acute ischemic stroke (AIS) with safety and efficacy.

Methods: A meta-analysis was performed to explore the value of tenecteplase and alteplase in AIS treatment. Medline, Embase, and Cochrane Library from January 2001 to April 2018 were searched for randomized controlled trials (RCTs) with tenecteplase vs alteplase for AIS.

Results: The primary outcomes were early neurological improvement at $24 \mathrm{~h}$ and functional outcome at 3 months. We pooled 1,390 patients from four RCTs. Tenecteplase showed a significant early neurological improvement $(P=0.035)$ compared with alteplase. In addition, tenecteplase showed a neutral effect on excellent outcome $(P=0.309)$, good functional outcome $(P=0.275)$, and recanalization $(P=0.3)$. No significant differences in safety outcomes were demonstrated. In subgroup analysis, $0.25 \mathrm{mg} / \mathrm{kg}$ dose of tenecteplase showed a significantly increased early neurological improvement $(P<0.001)$. In serious stroke at baseline (National Institutes of Health Stroke Scale [NIHSS] >12) subgroup, tenecteplase showed a dramatic early neurological improvement $(P=0.002)$ and low risks of any intracranial hemorrhage (ICH) $(P=0.027)$.

Conclusion: Tenecteplase provided better early neurological improvement than alteplase. The $0.25 \mathrm{mg} / \mathrm{kg}$ dose of tenecteplase subgroup specially showed better early neurological improvement and lower any ICH tendency than that of alteplase. In addition, in serious stroke at baseline subgroup, tenecteplase showed a lower risk of any ICH.

Keywords: tenecteplase, alteplase, acute ischemic stroke, early neurological improvement, meta-analysis

\section{Introduction}

Acute ischemic stroke (AIS) is a high mortality and high disability disease, the most common stroke subtype, life-threatening illness, with large financial burdens. ${ }^{1}$ Alteplase is a thrombolytic drug used primarily to treat AIS and acute myocardial infarction. ${ }^{2,3}$ Alteplase is a second-generation drug, which selectively activates fibrin-bound plasminogen to facilitate thrombolysis and recanalize the occluded blood vessels. ${ }^{4}$ However, intravenous alteplase increases the risk of bleeding, especially intracranial hemorrhage (ICH). ${ }^{5}$ Therefore, many new thrombolytic drugs are currently compared with alteplase on whether these new drugs have better safety and efficacy. ${ }^{6-9}$ Tenecteplase is one of these new drugs.

Tenecteplase is a multipoint variant of tissue plasminogen activator (t-PA). It is a third-generation fibrinolytic agent and is used clinically for the treatment of thrombolysis. In addition, models of fibrinolysis show that the bolus injection of tenecteplase is better than the infusion of t-PA. ${ }^{10}$ Preclinical studies have indicated that tenecteplase has a better thrombolytic effect, faster recanalization, and lower bleeding risk. ${ }^{11}$

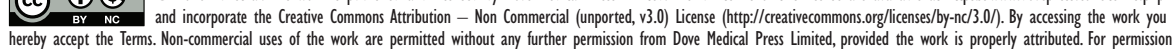
for commercial use of this work, please see paragraphs 4.2 and 5 of our Terms (https://www.dovepress.com/terms.php). 
These beneficial results stimulated enthusiasm for the clinical transformation of the drug to humans. ${ }^{12}$ These clinical studies explore whether tenecteplase has better efficacy and safety than alteplase. ${ }^{6-9}$ The Phase IIB/III trial ${ }^{6}$ randomly assigned AIS patients (symptom onset $<3 \mathrm{~h}$ ) to receive fixed doses in $0.1,0.25$, and $0.4 \mathrm{mg} / \mathrm{kg}$. This prematurely terminated clinical trial has demonstrated the potential efficiency in selecting a propitious dose for future study of a new thrombolytic agent for AIS. However, due to the premature interruption of the study, no convincing results can be obtained. A study of a lower weight-adjusted dose of tenecteplase $(0.1$ and $0.25 \mathrm{mg} / \mathrm{kg}$ ) in the New England Journal of Medicine ${ }^{7}$ selected the patient based on the strict imaging criteria, which showed that tenecteplase had better recanalization and clinical prognosis than alteplase. Another Phase II trial ${ }^{8}$ investigated the efficacy and safety of $0.25 \mathrm{mg} / \mathrm{kg}$ tenecteplase for AIS in Lancet Neurology. However, the results suggested that tenecteplase and alteplase in neurological and radiological outcomes did not differ. However, it is hoped that there will be larger clinical samples to obtain more exact results for this study. In a recent large sample randomized controlled trial (RCT) study ${ }^{9}$ in Lancet Neurology, the clinical efficacy results of tenecteplase $(0.4 \mathrm{mg} / \mathrm{kg})$ were not superior to alteplase, and they had a similar safety profile. Because of the lower baseline National Institutes of Health Stroke Scale (NIHSS) scores in this study, further studies are recommended to explore patients with more severe ischemic stroke.

Based on the above results, the efficacy and safety of tenecteplase over alteplase in the treatment of AIS are unclear. Several problems need to be solved, including the optimal dosage of tenecteplase and the efficacy and safety of the two drugs. The meta-analysis pooled data from previous randomized clinical trials to investigate whether the value of tenecteplase treatment for AIS is superior to alteplase in the onset of symptoms and to explore the potential factors that might influence the efficacy and safety of tenecteplase.

\section{Methods}

\section{Study protocol}

At the beginning of this project, a study protocol was drafted following the Cochrane Collaboration format. ${ }^{13}$

\section{Eligibility criteria}

Inclusion criteria were as follows: 1) study type (RCT); 2) language restriction (only English was available); 3) participants (patients with stroke); 4) intervention (tenecteplase or alteplase); and 5) outcomes (excellent and favorable outcomes based on modified Rankin scale [mRS] and early neurological improvement based on a major neurological improvement [MNI] or NIHSS of $\geq 8$ points or an NIHSS score of 0 or 1 at $24 \mathrm{~h}$ posttreatment, recanalization, and adverse events). Exclusion criteria were as follows: 1) study types (case reports, case reviews, retrospective studies, and cohort studies) and 2) the intervention of control group (placebo).

\section{Search strategy and information sources}

Three major databases, such as Medline, Embase, and Cochrane Library, were systematically searched by two independent authors (NX and ZC). The search strategy of the Medline was the combination of the variables "tenecteplase" OR "alteplase" AND "Stroke". Searches were limited to clinical trials and matched the titles and abstracts of studies. The search strategy for Embase and the Cochrane Library were similar to that used for Medline. In addition, two investigators (NX and ZC) independently manually screened reference lists from RCTs and systematic reviews to ensure all relevant studies had been included in this study.

\section{Study selection and data collection}

All records from the systematic search in the electronic database and reference lists of RCTs and systematic reviews were evaluated by two authors (NX and ZC) independently in accordance with the eligibility criteria as mentioned earlier. After strict selection and evaluation, the data were extracted from the included RCTs as follows: basic information on the included trials, inclusion and exclusion criteria for the participants, study design, and outcome assessments (Table 1).

\section{Outcomes of interest}

The primary efficacy outcomes were excellent functional outcomes, which were defined as mRS $0-1$ at 3 months. Secondary efficacy outcomes included good functional outcome (mRS 0-2 at 3 months), early neurological improvement at $24 \mathrm{~h}$, which was defined as an improvement on the NIHSS of $\geq 8$ points or an NIHSS score of 0 or 1 at $24 \mathrm{~h}$ posttreatment and recanalization within $24 \mathrm{~h}$. The primary safety endpoint was ICH, including symptomatic ICH (sICH) and any ICH. sICH was defined as the Safe Implementation of Thrombolysis in Stroke Monitoring Study (SITS-MOST) ${ }^{14}$ criteria (parenchymal hemorrhage type 2 or remote parenchymal hemorrhage type 2 on $24-48$ h noncontrast computed tomography [CT], with the neurological deterioration of $\geq 4$ points NIHSS score). Any ICH was defined as any ICH on the follow-up CT postthrombolysis. Secondary safety outcomes included dependence (mRS 3-5) and death rate at 
Table I Characteristics of the included studies and outcome events

\begin{tabular}{|c|c|c|c|c|}
\hline Trials & $\begin{array}{l}\text { Haley et al }(2010)^{6} \\
(\text { NCT00252239) }\end{array}$ & $\begin{array}{l}\text { Parsons et al }(2012)^{7} \\
(\text { ACTRN I 2608000466347) }\end{array}$ & $\begin{array}{l}\text { Huang et al }(20 \mid 5)^{8} \\
\text { (NCT0I } 472926)\end{array}$ & $\begin{array}{l}\text { Logallo et al }(2017)^{9} \\
\text { (NCT01949948) }\end{array}$ \\
\hline \multicolumn{5}{|c|}{ I. Information of the included trials } \\
\hline Regions & 8 centers in Japan & 3 centers in Australia & Single center in the UK & 13 centers in Norway \\
\hline Phases & $\| \mathrm{IB} / \mathrm{II}$ & IIB & II & III \\
\hline Publication & Stroke & New England Journal of Medicine & Lancet Neurology & Lancet Neurology \\
\hline \multicolumn{5}{|c|}{ 2. Eligibility criteria and study design } \\
\hline $\begin{array}{l}\text { Inclusion } \\
\text { criteria }\end{array}$ & $\begin{array}{l}\text { Acute ischemic stroke; } \\
\text { symptom onset }<3 \mathrm{~h} ; \\
\text { NIHSS }>0 \text {; if NIHSS }=\mathrm{I} \text {, } \\
\text { requires significant deficit }\end{array}$ & $\begin{array}{l}\text { Acute ischemic stroke; symptom } \\
\text { onset }<6 \text { h; NIHSS: } 4-24 ; \mathrm{mRS} \\
0-2 ; \text { core volume }<\mathrm{I} / 3 \text { of MCA or } \\
\text { I/2 ACA/PCA territory; perfusion } \\
\text { volume }>\text { I } 20 \% \text { core and } \geq 20 \mathrm{~mL} \text {; } \\
\text { occlusion of MCA/ACA/PCA }\end{array}$ & $\begin{array}{l}\text { Acute ischemic stroke; } \\
\text { time window }<4.5 \mathrm{~h} \text {; } \\
\text { NIHSS I-25; mRS 0-2 }\end{array}$ & $\begin{array}{l}\text { Acute ischemic stroke; } \\
\text { symptom onset } \\
\text { or awakening with } \\
\text { symptoms }<4.5 \mathrm{~h} ; \\
\text { age } \geq \text { I } 8 \text { years; NIHSS }>0\end{array}$ \\
\hline $\begin{array}{l}\text { Exclusion } \\
\text { criteria }\end{array}$ & $\begin{array}{l}\text { Stroke in previous } \\
3 \text { months; seizures at the } \\
\text { onset of stroke }\end{array}$ & $\begin{array}{l}\text { Stroke in previous } 3 \text { months; } \\
\text { eGFR }<15 \mathrm{~mL} / \mathrm{min} \text {; contraindication } \\
\text { for MRI }\end{array}$ & $\begin{array}{l}\text { Recent stroke on } \\
\text { NCCT; hypodensity } \\
\text { of }>\mathrm{I} / 3 \text { of the MCA } \\
\text { territory; ASPECT } \\
\text { score } \leq 4 \text {; glucose } \\
>18 \mathrm{mmol} / \mathrm{L} \text {; eGFR } \\
<30 \mathrm{~mL} / \mathrm{min} \text {; allergy } \\
\text { to iodinated contrast }\end{array}$ & $\begin{array}{l}\text { mRS score } \geq 3 \text {; NIHSS } \\
\text { cannot be obtained; no } \\
\text { arterial occlusion on } \\
\text { baseline } \mathrm{CT} \text {; ICH; SAH; } \\
\text { large areas of ischemic; } \\
\text { any serious medical illness }\end{array}$ \\
\hline $\begin{array}{l}\text { Study } \\
\text { design }\end{array}$ & $\begin{array}{l}\text { Tenecteplase } 0.1 \text {, } \\
0.25 \text {, and } 0.4 \mathrm{mg} / \mathrm{kg} \text { vs } \\
\text { alteplase } 0.9 \mathrm{mg} / \mathrm{kg}\end{array}$ & $\begin{array}{l}\text { Tenecteplase } 0.1 \text { or } 0.25 \mathrm{mg} / \mathrm{kg} \text { or } \\
\text { alteplase } 0.9 \mathrm{mg} / \mathrm{kg}\end{array}$ & $\begin{array}{l}\text { Tenecteplase } 0.25 \mathrm{mg} / \\
\mathrm{kg} \text { (maximum } 25 \mathrm{mg} \text { ) } \\
\text { or alteplase } 0.9 \mathrm{mg} / \mathrm{kg} \\
\text { (maximum of } 90 \mathrm{mg} \text { ) }\end{array}$ & $\begin{array}{l}\text { Tenecteplase } 0.4 \mathrm{mg} / \mathrm{kg} \\
\text { (to a maximum of } 40 \mathrm{mg} \text { ) } \\
\text { or alteplase } 0.9 \mathrm{mg} / \mathrm{kg} \\
\text { (to a maximum of } 90 \mathrm{mg} \text { ) }\end{array}$ \\
\hline \multicolumn{5}{|c|}{ 3. Outcomes assessments } \\
\hline $\begin{array}{l}\text { Efficacy } \\
\text { outcomes }\end{array}$ & $\begin{array}{l}\text { Favorable outcome, } \\
3 \text { months Rankin good } \\
\text { and poor and } 24 \mathrm{~h}(\mathrm{MNI})\end{array}$ & $\begin{array}{l}\text { Reperfusion at } 24 \mathrm{~h}, \mathrm{NIHSS} \text {, infarct } \\
\text { growth at } 24 \mathrm{~h} \text {, infarct growth at } \\
90 \text { days, complete recanalization } \\
\text { at } 24 \mathrm{~h} \text {, complete or partial } \\
\text { recanalization at } 24 \mathrm{~h}, \mathrm{MNI}\end{array}$ & $\begin{array}{l}\text { Percentage penumbra } \\
\text { at } 24-48 \mathrm{~h} \text {, infarct } \\
\text { volume on } 24-48 \mathrm{~h} \\
\mathrm{NCCT}, \mathrm{mRS} \text { response } \\
\text { ( } 30 \text { and } 90 \text { days), } \\
\text { NIHSS response, } \\
\text { excellent ( } 0-\mathrm{I} \text { points } \\
\text { of mRS) functional } \\
\text { outcome at } 30 \text { and } \\
90 \text { days, mean home } \\
\text { time by } 90 \text { days }\end{array}$ & $\begin{array}{l}\text { Excellent ( } 0-I \text { points of } \\
\text { mRS) functional outcome } \\
\text { at } 3 \text { months, mRS } \\
\text { response, change in NIHSS }\end{array}$ \\
\hline $\begin{array}{l}\text { Safety } \\
\text { outcomes }\end{array}$ & $\begin{array}{l}\text { sICH, asymptomatic } \mathrm{ICH} \text {, } \\
\text { all hemorrhage, major } \\
\text { systemic bleeding, and } \\
\text { death at } 3 \text { months }\end{array}$ & $\begin{array}{l}\text { Large parenchymal hematoma, any } \\
\text { parenchymal hematoma, } \mathrm{sICH} \text {, poor } \\
\text { outcome at } 90 \text { days and death }\end{array}$ & $\begin{array}{l}\text { Any ICH, any } \\
\text { parenchymal } \\
\text { hemorrhage type 2, } \\
\text { sICH }\end{array}$ & $\begin{array}{l}\text { Any intracranial } \\
\text { hemorrhage occurring } \\
\text { within } 24-48 \mathrm{~h}, \mathrm{sICH} \\
\text { occurring within } 24-48 \mathrm{~h} \text {, } \\
\text { and death at } 90 \text { days }\end{array}$ \\
\hline
\end{tabular}

Abbreviations: ACA, anterior cerebral artery; $\mathrm{CT}$, computed tomography; eGFR, estimated glomerular filtration rate; ICH, intracranial hemorrhage; $M C A$, middle cerebral artery; MNI, major neurological improvement; MRI, magnetic resonance imaging; mRS, modified Rankin scale; NCCT, noncontrast computed tomography; NIHSS, National Institutes of Health Stroke Scale; PCA, posterior cerebral artery; SAH, subarachnoid hemorrhage; sICH, symptomatic ICH.

Day 90. In subgroup analysis, we set the relevant cutoff values that could distinctly affect the effectiveness of tenecteplase or alteplase and stratified the included trials into low $(<45 \%)$ and high ( $\geq 45 \%)$ percentage of patients with hypertension, high stroke severity at baseline (NIHSS $\geq 12$ ), and low stroke severity at baseline (NIHSS $<12$ ) (Table 2).

\section{Risk of bias}

The risk of bias plot in individual studies was created using the Review Manager 5.2 software. For assessing the risk of bias of RCTs, we applied uniform criteria of the Cochrane Collaboration, which included selection bias, performance bias, detection bias, attrition bias, reporting bias, and other potential biases.

\section{Summary measures and synthesis of results}

STATA (version 12.0) was used to assess the data. Dichotomous outcomes were analyzed as the risk ratio (relative risk [RR]; 95\% confidence interval [CI]) and calculated using a 
Table 2 Subgroup analysis of efficacy and safety outcomes

\begin{tabular}{|c|c|c|c|c|c|c|c|c|}
\hline \multirow[t]{3}{*}{ Subgroup } & \multicolumn{8}{|c|}{ Efficacy outcomes } \\
\hline & \multicolumn{2}{|c|}{$\begin{array}{l}\text { Excellent functional } \\
\text { outcome }\end{array}$} & \multicolumn{2}{|c|}{$\begin{array}{l}\text { Good functional } \\
\text { outcome }\end{array}$} & \multicolumn{2}{|c|}{$\begin{array}{l}\text { Early neurological } \\
\text { improvement }\end{array}$} & \multicolumn{2}{|l|}{ Recanalization } \\
\hline & RR (95\% Cl) & $P$-value & RR (95\% Cl) & $P$-value & RR (95\% Cl) & $P$-value & $\mathbf{R R}(95 \% \mathrm{Cl})$ & $P$-value \\
\hline \multicolumn{9}{|c|}{ I. Stroke severity at baseline } \\
\hline $\mathrm{NIHSS} \geq 12$ & $1.30(0.91,1.88)$ & 0.154 & $1.25(0.69,2.27)$ & 0.464 & $1.71(1.21,2.43)$ & 0.002 & $1.13(0.89,0.42)$ & 0.322 \\
\hline $\mathrm{NIHSS}<12$ & $1.03(0.95,1.13)$ & 0.480 & $1.08(0.82,1.42)$ & 0.575 & $1.50(0.68,3.33)$ & 0.319 & N/A & $N / A$ \\
\hline \multicolumn{9}{|l|}{ 2. Hypertension } \\
\hline$N \geq 45$ & $1.03(0.94,1.13)$ & 0.520 & $1.30(0.95,1.77)$ & 0.104 & $1.07(0.93,1.24)$ & 0.332 & $N / A$ & $N / A$ \\
\hline \multirow[t]{4}{*}{$\mathrm{N}<45$} & $1.17(0.91,1.50)$ & 0.223 & $1.13(0.79,1.61)$ & 0.510 & $\mathrm{I} .83(\mathrm{I} .34,2.5 \mathrm{I})$ & 0.000 & $1.13(0.89,0.42)$ & 0.322 \\
\hline & \multicolumn{8}{|c|}{ Safety outcomes } \\
\hline & \multicolumn{2}{|l|}{ sICH } & \multicolumn{2}{|l|}{ Any ICH } & \multicolumn{2}{|l|}{ Dependence } & \multicolumn{2}{|l|}{ Mortality } \\
\hline & $\operatorname{RR}(95 \% \mathrm{Cl})$ & $P$-value & $\operatorname{RR}(95 \% \mathrm{Cl})$ & $P$-value & $\operatorname{RR}(95 \% \mathrm{Cl})$ & $P$-value & $\operatorname{RR}(95 \% \mathrm{CI})$ & $\overline{P \text {-value }}$ \\
\hline \multicolumn{9}{|c|}{ 3. Stroke severity at baseline } \\
\hline $\mathrm{NIHSS} \geq 12$ & $0.38(0.10,1.38)$ & 0.140 & $0.48(0.25,0.92)$ & 0.027 & $0.67(0.34,1.34)$ & 0.260 & I.0I $(0.47,2.16)$ & $0.98 I$ \\
\hline $\mathrm{NIHSS}<12$ & $1.29(0.67,2.46)$ & 0.447 & $0.95(0.68,1.33)$ & 0.759 & $\mathrm{I} .05(0.84, \mathrm{I} .3 \mathrm{I})$ & 0.673 & $0.90(0.55,1.47)$ & 0.668 \\
\hline \multicolumn{9}{|l|}{ 4. Hypertension } \\
\hline $\mathrm{N} \geq 45$ & $1.15(0.55,2.40)$ & 0.702 & $0.94(0.65,1.38)$ & 0.764 & $1.07(0.83,1.38)$ & 0.614 & $1.12(0.67,1.88)$ & 0.668 \\
\hline $\mathrm{N}<45$ & $0.76(0.24,2.46)$ & 0.648 & $0.63(0.35,1.15)$ & 0.132 & $0.79(0.52,1.20)$ & 0.271 & $0.79(0.49,1.29)$ & 0.350 \\
\hline
\end{tabular}

Abbreviations: $\mathrm{Cl}$, confidence interval; ICH, intracranial hemorrhage; N/A, not applicable; NIHSS, National Institutes of Health Stroke Scale; RR, relative risk; sICH, symptomatic ICH.

random effect model. Statistical heterogeneity was estimated by the $I^{2}$ statistic as follows: $I^{2}<30 \%$ means "low heterogeneity", $I^{2}=30 \%-50 \%$ denotes "moderate heterogeneity", and $I^{2}>50 \%$ represents "substantial heterogeneity". Subgroup analyses were implemented to detect the dose of drug administration and the severity of stroke and hypertension. Sensitivity analysis was used to explore the stability of the consolidated results. Tests were two-tailed, and a $P$-value of $<0.05$ was considered significant for all analyses.

\section{Results}

A total of 513 titles and abstracts were identified through Medline, Embase, and Cochrane Library (Figure 1). After removing the duplicates and irrelevant records, 17 fulltext articles were assessed for eligibility. Additionally, the following 13 articles were excluded due to the limitation of publication types: three protocol studies, one post hoc analysis, one meta-analysis, seven comments, and eight reviews. Ultimately, four RCTs containing 1,390 patients were included in qualitative synthesis (Figure 1). The main characteristics of the included studies are listed in Table 1.

\section{Outcomes analysis}

All four RCTs enrolling 1,390 patients were available for the analysis of efficacy and safety outcomes.

Tenecteplase showed a neutral effect on excellent functional outcome (58.7 vs 55.6\% for tenecteplase vs alteplase; RR 1.04; 95\% CI: 0.96, 1.14; $P=0.309$; Figure 2A) and good functional outcome (70.8 vs $68.6 \%$ for tenecteplase vs alteplase; RR
1.16; 95\% CI: 0.89, 1.53; $P=0.275$; Figure 2B). Tenecteplase showed a significantly early neurological improvement at $24 \mathrm{~h}$ (40.6 vs 33.9\% for tenecteplase vs alteplase; RR 1.52; 95\% CI: $1.03,2.25 ; P=0.035$; Figure $2 \mathrm{C}$ ) compared with alteplase. In addition, tenecteplase showed a neutral effect on recanalization within 24 or $24-48 \mathrm{~h}$ ( 61.8 vs $54.9 \%$ for tenecteplase vs alteplase; RR 1.26; 95\% CI: 0.53, 3.01; $P=0.3$; Figure 2D). No significant differences in other safety outcomes were demonstrated (Figure 3 ). These safety outcomes include sICH (3.1 vs 3.2\% for tenecteplase vs alteplase; RR 0.99; $95 \%$ CI: 0.53 , 1.86 ; $P=0.968$; Figure $3 \mathrm{~A}$ ), any ICH ( 9.6 vs $11.9 \%$ for tenecteplase vs alteplase; RR 0.77; 95\% CI: 0.52, 1.15; $P=0.202$; Figure 3B), dependence ( 21.4 vs $22.7 \%$ for tenecteplase vs alteplase; RR 0.89; 95\% CI: 0.66, 1.19; $P=0.437$; Figure 3C), and mortality ( 7.2 vs $8.1 \%$ for tenecteplase vs alteplase; RR 0.93; 95\% CI: 0.65, 1.33; $P=0.699$; Figure 3D). The heterogeneity of good functional outcome $\left(I^{2}=73.1 \%, P=0.011\right.$; Figure $2 \mathrm{~B})$, the early neurological improvement $\left(I^{2}=70.3 \%\right.$, $P=0.018$; Figure $2 \mathrm{C})$, recanalization within 24 or $24-48 \mathrm{~h}$ at $24 \mathrm{~h}\left(I^{2}=88.6 \%, P=0.0033\right.$; Figure $\left.2 \mathrm{D}\right)$, and dependence $\left(I^{2}=50.2 \%, P=0.11\right.$; Figure $\left.3 \mathrm{C}\right)$ were apparent. To detect the source of the statistical heterogeneity, sensitivity analysis was performed. The sensitivity analysis showed that all the consolidated results were stable (Figure S1).

\section{Subgroup analysis}

A subgroup analysis was performed to examine the influence of tenecteplase dosage, NIHSS score at baseline, and hypertension. Tenecteplase dosage did not influence most 


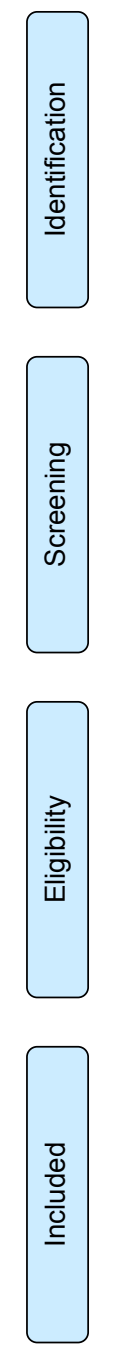

Records identified through
MEDLINE and EMBASE

searching $(n=462)$

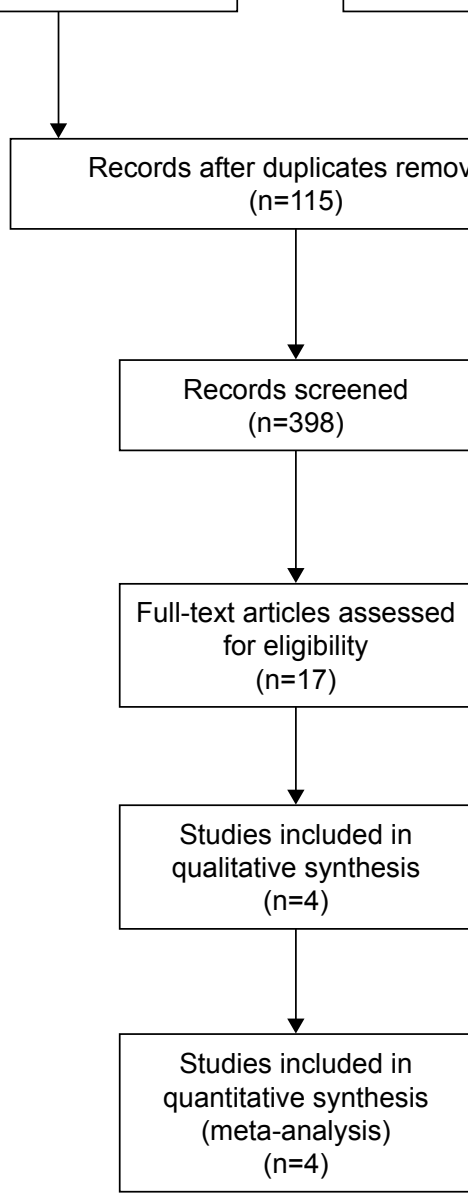

Additional records identified through Cochrane Library $(n=51)$

Figure I The study search, selection, and inclusion process.

efficacy outcomes (Figure 4-1A-C, 4-2A-C, 4-3A and C and $4-4 \mathrm{~A}$ and $\mathrm{B}$ ), except that $0.25 \mathrm{mg} / \mathrm{kg}$ dose of tenecteplase showed a significantly increased early neurological improvement ( 47.2 vs $22.2 \%$ for tenecteplase vs alteplase; RR 2.1; 95\% CI: 1.43, 3.09; $P<0.001$; Figure 4-3B). Tenecteplase dosage did not influence safety outcomes (Figure 5), but $0.25 \mathrm{mg} / \mathrm{kg}$ dose of tenecteplase subgroup showed a trend for lower risk of any ICH (12.0 vs $22.2 \%$ for tenecteplase vs alteplase; RR 0.57; 95\% CI: 0.30, 1.06; $P=0.076$; Figure 5-2B). Serious stroke symptoms at baseline (NIHSS $>12$ ) showed a dramatic early neurological improvement at $24 \mathrm{~h}$ (50.0 vs $29.4 \%$ for tenecteplase vs alteplase; RR 1.71; 95\% CI: 1.21, 2.43; $P=0.002$; Table 2) but low risks of any ICH ( 10.8 vs $23.5 \%$ for tenecteplase vs alteplase; RR 0.48; 95\% CI: 0.25, 0.92; $P=0.027$; Table 2). In addition, hypertension (number of hypertension patients/ total patients $<45 \%$ ) had an apparent early neurological improvement at $24 \mathrm{~h}$ (37.4 vs $20.0 \%$ for tenecteplase vs alteplase; RR 1.83; 95\% CI: 1.34, 2.51; $P<0.001$; Table 2). The sensitivity analysis showed that the different doses of tenecteplase subgroup results were stable (Figure S2).

\section{Risk of bias in included studies}

Full details about the risk of bias of the included studies are shown in Figure 6. For allocation concealment, the risk of bias of one trial was unclear, and another trial had a high risk of bias. For the blinding of outcomes assessment, the risk of bias was high in two studies. For incomplete outcome data, the risk of bias was unclear in one study. Apart from these three items, no high or unclear risk of bias was observed in any of the other items.

\section{Discussion}

Based on the data gathered from the four published RCTs including 1,390 individuals, our present meta-analysis showed that tenecteplase was superior to alteplase in early 


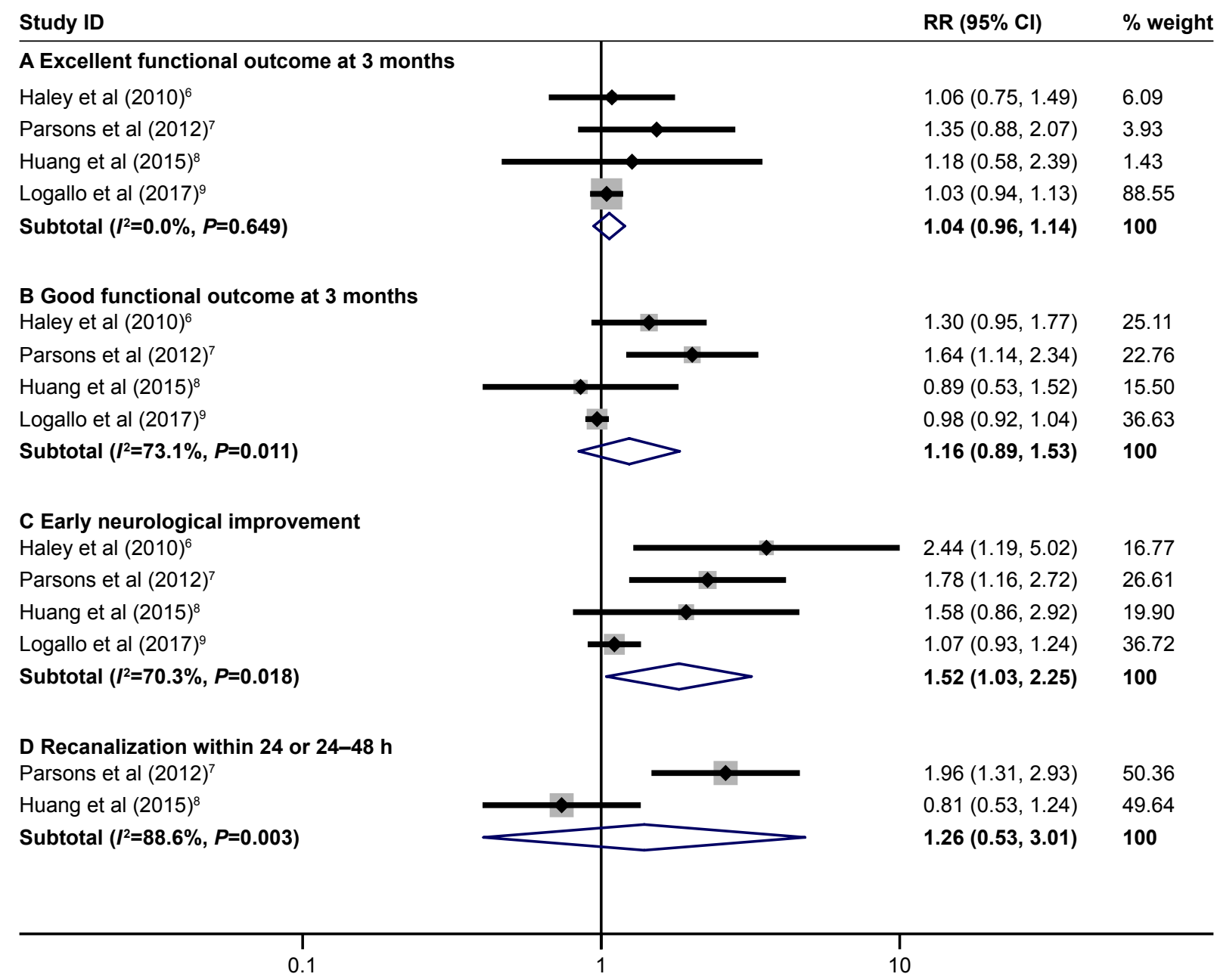

Figure 2 The pooled RR of the efficacy outcomes.

Notes: The black diamond indicates the estimated RR for each RCT. The gray box around each diamond indicates the estimated weight of each RCT, and the extending lines indicate the estimated $95 \% \mathrm{Cl}$ of RR for each RCT. The diamond indicates the estimated RR $(95 \% \mathrm{Cl})$ for all patients together. (A) Excellent favorable outcome. (B) Good functional outcome. (C) Early neurological improvement. (D) Recanalization within 24 or 24-48 h. Weights are from random-effects analysis.

Abbreviations: $\mathrm{Cl}$, confidence interval; $\mathrm{RCT}$, randomized controlled trial; RR, relative risk.

neurological improvement. There was no significant difference between tenecteplase and alteplase in other efficacy items and all safety items. Different doses of tenecteplase subgroup analysis showed that the $0.25 \mathrm{mg} / \mathrm{kg}$ dose of tenecteplase was significantly better than alteplase in terms of early neurological improvement. Although previous meta-analysis had reached similar conclusions, ${ }^{12}$ the number of patients in this meta-analysis was 1,100 more than the number of patients in the previous meta-analysis from four RCT studies. In addition, we not only compared different dose subgroups but also performed NIHSS score at baseline subgroup and percentage of hypertension patients' subgroup analyses to further explore the relevant factors affecting clinical efficacy and safety of tenectplase and alteplase. Surprisingly, in the subgroup with a higher NIHSS score at baseline, the risk of any ICH with tenecteplase was lower than that of alteplase.

In the previous meta-analysis, ${ }^{12}$ there was a potential correlation between drug dose and ICH risk, but small numbers (19 patients) of high doses $(0.4 \mathrm{mg} / \mathrm{kg}$ ) of tenecteplase did not give credible results. However, the latest RCT study, ${ }^{9}$ 549 patients in the high-dose group of tenecteplase, increased the reliability of the assessment of high-dose subgroup and its influence on ICH risk. Why did the previous study use less high dose of tenecteplase as thrombolytic therapy for AIS? The choice of the early thrombolytic drug dose was often based on the study of small samples. ${ }^{15-18}$ When the higher dose group had more serious complications, the dose study was abandoned. Previous experience had taught us that the use of higher dose of thrombolytic drugs often led 


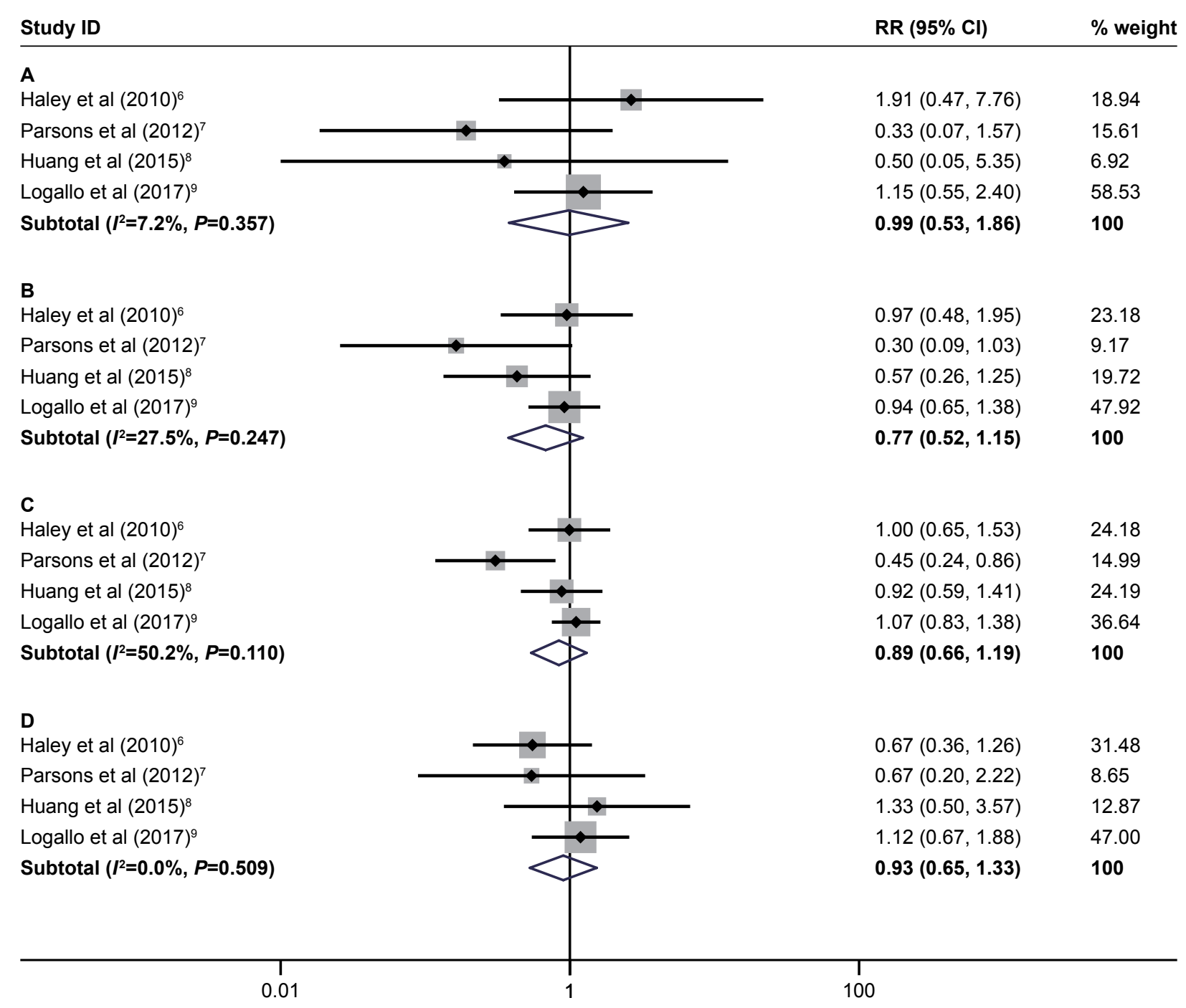

Figure 3 The pooled RR of the safety outcomes.

Notes: The black diamond indicates the estimated RR for each RCT. The gray box around each diamond indicates the estimated weight of each RCT, and the extending lines indicate the estimated $95 \% \mathrm{Cl}$ of RR for each RCT. The diamond indicates the estimated RR (95\% Cl) for all patients together. (A) sICH. (B) Any ICH. (C) Dependence. (D) Mortality. Weights are from random-effects analysis.

Abbreviations: $\mathrm{Cl}$, confidence interval; ICH, intracranial hemorrhage; RCT, randomized controlled trial; RR, relative risk; sICH, symptomatic ICH.

to higher risks of $\mathrm{ICH} .{ }^{19}$ Therefore, doctors are often cautious when using high drug doses with probable serious side effects. However, in the latest large sample $\mathrm{RCT}^{9}$ in Lancet Neurology, when the high dose of tenecteplase was used, it did not increase the risk of ICH. In addition, there was no significant difference in dependence and mortality after 3 months at AIS. ${ }^{9}$ These new data demonstrated that increasing the dose concentration of tenecteplase did not increase the risk of ICH. This evidence may provide an indicator that high dose of tenecteplase could be used in clinical treatment and has important clinical significance.

Thrombolytic therapy is based on the hypothesis that recanalization of the infarct vessels is for salvageable of ischemic penumbra. ${ }^{20}$ Hence, in the treatment of AIS, recanalization is an important indicator of efficacy. In this meta-analysis, we increased the assessment of recanalization but unfortunately only had the study data for the 0.1 and $0.25 \mathrm{mg} / \mathrm{kg}$ dose groups. Although Parsons et al' $\mathrm{s}^{7}$ study supported the possibility that there may be tenecteplase dosedependent recanalization, there was no study on the high-dose tenecteplase group with recanalization, which means that no result had reached statistical significance. In the latest RCT study included in this meta-analysis, ${ }^{9}$ the study of $0.4 \mathrm{mg} / \mathrm{kg}$ dose tenecteplase did not have appropriate clinical data for recanalization, and it was not possible to conclude that high dose of tenecteplase can promote recanalization. In addition, 
1A Excellent functional outcome at 3 months $0.1 \mathrm{mg} / \mathrm{kg}$ Haley et al $(2010)^{6}$

Parsons et al $(2012)^{7}$

Subtotal $\left(I^{2}=0.0 \%, P=0.698\right)$

1B Excellent functional outcome at 3 months $0.25 \mathrm{mg} / \mathrm{kg}$ Haley et al $(2010)^{6}$

Parsons et al (2012)

Huang et al $(2015)^{8}$

Subtotal $\left(I^{2}=0.0 \%, P=0.463\right)$

1C Excellent functional outcome at 3 months $0.4 \mathrm{mg} / \mathrm{kg}$ Haley et al $(2010)^{6}$

Logallo et al $(2017)^{9}$

Subtotal $\left(I^{2}=0.0 \%, P=0.667\right)$

2A Good functional outcome at 3 months $0.1 \mathrm{mg} / \mathrm{kg}$ Haley et al $(2010)^{6}$

Parsons et al $(2012)^{7}$

Subtotal $\left(I^{2}=0.0 \%, P=0.913\right)$

2B Good functional outcome at 3 months $0.25 \mathrm{mg} / \mathrm{kg}$ Haley et al $(2010)^{6}$

Parsons et al (2012)

Huang et al $(2015)^{8}$

Subtotal $\left(I^{2}=55.4 \%, P=0.106\right)$

2C Good functional outcome at 3 months $0.4 \mathrm{mg} / \mathrm{kg}$ Haley et al $(2010)^{6}$

Logallo et al $(2017)^{9}$

Subtotal $\left(I^{2}=0.0 \%, P=0.652\right)$

3A Early neurological improvement $0.1 \mathrm{mg} / \mathrm{kg}$ Haley et al $(2010)^{6}$

Parsons et al $(2012)^{7}$

Subtotal $\left(I^{2}=0.0 \%, P=0.366\right)$

3B Early neurological improvement $0.25 \mathrm{mg} / \mathrm{kg}$

Haley et al $(2010)^{6}$

Parsons et al (2012)

Huang et al $(2015)^{8}$

Subtotal $\left(I^{2}=0.0 \%, P=0.401\right)$

3C Early neurological improvement $0.4 \mathrm{mg} / \mathrm{kg}$ Haley et al (2010)

Logallo et al $(2017)^{9}$

Subtotal $\left(I^{2}=0.0 \%, P=0.765\right)$

4A Recanalization within 24 or $24-48$ h $0.1 \mathrm{mg} / \mathrm{kg}$ Parsons et al (2012) 7

Subtotal (N/A)

4B Recanalization within 24 or 24-48 h 0.25 mg/kg

Parsons et al (2012) ${ }^{7}$

Huang et al $(2015)^{8}$

Subtotal $\left(I^{2}=85.7 \%, P=0.008\right)$

Overall $\left(I^{2}=48.2 \%, P=0.005\right)$

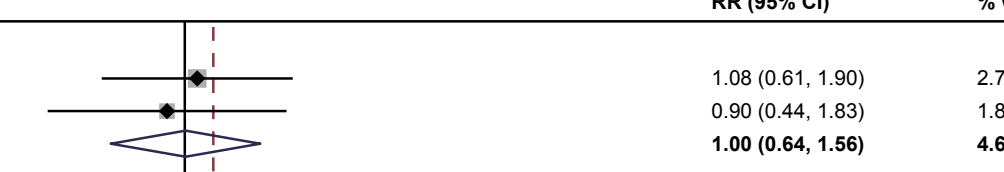

$1.15(0.66,2.00) \quad 2.91$

$1.80(1.05,3.08) \quad 3.03$

$1.18(0.58,2.39) \quad 1.91$

$1.38(0.99,1.94)$

$0.88(0.43,1.80) \quad 1.84$

$1.03(0.94,1.13)$

$1.03(0.94,1.12) \quad 16.46$

$1.31(0.78,2.21)$

$1.36(0.79,2.35) \quad 2.96$

$1.33(0.91,1.95) \quad 6.13$

$1.38(0.83,2.31) \quad 3.30$

$1.91(1.19,3.07) \quad 3.71$

$0.89(0.53,1.52) \quad 3.11$

$1.35(0.87,2.09) \quad 10.11$

$1.13(0.60,2.12) \quad 2.33$

$0.98(0.92,1.04) \quad 15.44$

$0.98(0.92,1.04) \quad 17.78$

$2.33(0.66,8.21) \quad 0.65$

$1.22(0.62,2.42) \quad 2.02$

$1.42(0.78,2.59) \quad 2.67$

$3.67(1.13,11.88) \quad 0.74$

$2.33(1.35,4.04) \quad 2.93$

$1.58(0.86,2.92) \quad 2.45$

$2.10(1.43,3.09) \quad 6.12$

$1.33(0.32,5.47) \quad 0.52$

$1.07(0.93,1.24) \quad 12.46$

$1.08(0.93,1.24)$

$1.20(0.80,1.80)$

$1.20(0.80,1.80)$

$1.60(1.15,2.23) \quad 6.17$

$0.81(0.53,1.24)$

$1.15(0.56,2.35) \quad 10.50$

$1.18(1.07,1.31) \quad 100$

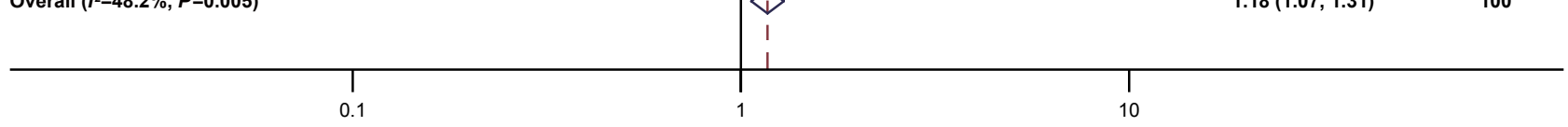

Figure 4 Subgroup analysis of the effect of tenecteplase (all doses) compared with alteplase on efficacy outcomes.

Notes: The black diamond indicates the estimated RR for each RCT. The gray box around each diamond indicates the estimated weight of each RCT, and the extending lines indicate the estimated $95 \% \mathrm{Cl}$ of RR for each RCT. The diamond indicates the estimated RR ( $95 \% \mathrm{Cl}$ ) for all patients together. (IA-C) Excellent functional outcome at 3 months with different doses of tenecteplase. (2A-C) Good functional outcome at 3 months with different doses of tenecteplase. (3A-C) Early neurological improvement with different doses of tenecteplase. (4A and B) Recanalization within 24 or 24-48 h with different doses of tenecteplase. Weights are from random-effects analysis.

Abbreviations: N/A, not applicable; $\mathrm{Cl}$, confidence interval; $\mathrm{RCT}$, randomized controlled trial; $\mathrm{RR}$, relative risk. 


\section{Study ID}

$1 \mathrm{~A} \mathrm{sICH} 0.1 \mathrm{mg} / \mathrm{kg}$

Haley et al $(2010)^{6}$

Parsons et al $(2012)^{7}$

Subtotal $\left(I^{2}=0.0 \%, P=1.000\right)$

$1 \mathrm{~B} \mathrm{sICH} 0.25 \mathrm{mg} / \mathrm{kg}$

Haley et al (2010)

Parsons et al (2012)

Huang et al (2015)

Subtotal $\left(I^{2}=0.0 \%, P=0.527\right)$

1C sICH $0.4 \mathrm{mg} / \mathrm{kg}$

Haley et al $(2010)^{6}$

Logallo et al $(2017)^{9}$

Subtotal $\left(I^{2}=33.6 \%, P=0.220\right)$

2A Any ICH $0.1 \mathrm{mg} / \mathrm{kg}$

Haley et al $(2010)^{6}$

Parsons et al $(2012)^{7}$

Subtotal $\left(I^{2}=0.0 \%, P=0.697\right)$

2B Any ICH 0.25 mg/kg

Haley et al $(2010)^{6}$

Parsons et al $(2012)^{7}$

Huang et al $(2015)^{8}$

Subtotal $\left(I^{2}=0.0 \%, P=0.522\right)$

$2 \mathrm{C}$ Any ICH $0.4 \mathrm{mg} / \mathrm{kg}$

Haley et al $(2010)^{6}$

Logallo et al $(2017)^{9}$

Subtotal $\left(I^{2}=26.7 \%, P=0.243\right)$

3A Dependence $0.1 \mathrm{mg} / \mathrm{kg}$

Haley et al $(2010)^{6}$

Parsons et al $(2012)^{7}$

Subtotal $\left(I^{2}=47.9 \%, P=0.166\right)$

3B Dependence 0.25 mg/kg

Haley et al (2010)

Parsons et al (2012)

Huang et al $(2015)^{8}$

Subtotal $\left(I^{2}=53.1 \%, P=0.119\right)$

3C Dependence $0.4 \mathrm{mg} / \mathrm{kg}$

Haley et al $(2010)^{6}$

Logallo et al $(2017)^{9}$

Subtotal $\left(I^{2}=0.0 \%, P=0.873\right)$

4A Mortality $0.1 \mathrm{mg} / \mathrm{kg}$

Haley et al $(2010)^{6}$

Parsons et al (2012)

Subtotal $\left(I^{2}=15.0 \%, P=0.278\right)$

4B Mortality $0.25 \mathrm{mg} / \mathrm{kg}$

Haley et al $(2010)^{6}$

Parsons et al (2012)

Huang et al (2015)

Subtotal $\left(I^{2}=0.0 \%, P=0.505\right)$

4C Mortality $0.4 \mathrm{mg} / \mathrm{kg}$

Haley et al $(2010)^{6}$

Logallo et al $(2017)^{9}$

Subtotal $\left(I^{2}=0.0 \%, P=0.364\right)$

Overall $\left(I^{2}=0.0 \%, P=0.561\right)$
RR $(95 \% \mathrm{Cl})$

$\%$ weight

$0.33(0.01,7.88)$

$0.33(0.04,2.99)$

$0.33(0.05,2.02)$

$2.00(0.19,20.93)$

$0.33(0.04,2.99)$

$0.50(0.05,5.35)$

$0.67(0.18,2.53)$

$4.89(0.55,43.73)$

$1.15(0.55,2.40)$

$1.62(0.49,5.39)$

$0.60(0.16,2.30)$

$0.40(0.09,1.87)$

$0.50(0.18,1.39)$

$0.80(0.24,2.70)$

$0.20(0.03,1.59)$

$0.57(0.26,1.25)$

$0.57(0.30,1.06)$

$1.89(0.63,5.74)$

$0.94(0.65,1.38)$

$1.09(0.63,1.91)$

$1.30(0.67,2.51)$

$0.64(0.30,1.37)$

$0.94(0.47,1.88)$

$0.60(0.25,1.45)$

$0.27(0.09,0.86)$

$0.92(0.59,1.41)$

$0.62(0.32,1.21)$

$1.14(0.52,2.49)$

$1.07(0.83,1.38)$

$1.08(0.84,1.37)$

$0.31(0.07,1.38)$

$1.00(0.22,4.49)$

$0.56(0.18,1.74)$

$0.88(0.36,2.12)$

$0.33(0.04,2.99)$

$1.33(0.50,3.57)$

$0.96(0.51,1.80)$

$0.61(0.18,2.03)$

$1.12(0.67,1.88)$

$1.02(0.63,1.64)$

$0.93(0.81,1.07)$

4.61

3.37

7.98

2.56

1.51

10.65

14.72

3.28

30.09

33.37

0.91

0.88

1.80

2.55

0.41

2.05

5.01

100

Figure 5 Subgroup analysis of the effect of tenecteplase (all doses) compared with alteplase on safety outcomes.

Notes: The black diamond indicates the estimated RR for each RCT. The gray box around each diamond indicates the estimated weight of each RCT, and the extending lines indicate the estimated $95 \% \mathrm{Cl}$ of RR for each RCT. The diamond indicates the estimated RR $(95 \% \mathrm{Cl})$ for all patients together. (IA-C) sICH with different doses of tenecteplase. (2A-C) Any ICH with different doses of tenecteplase. (3A-C) Dependence with different doses of tenecteplase. (4A-C) Mortality with different doses of tenecteplase. Weights are from random-effects analysis.

Abbreviations: $\mathrm{Cl}$, confidence interval; ICH, intracranial hemorrhage; $\mathrm{RCT}$, randomized controlled trial; $\mathrm{RR}$, relative risk; sICH, symptomatic ICH. 


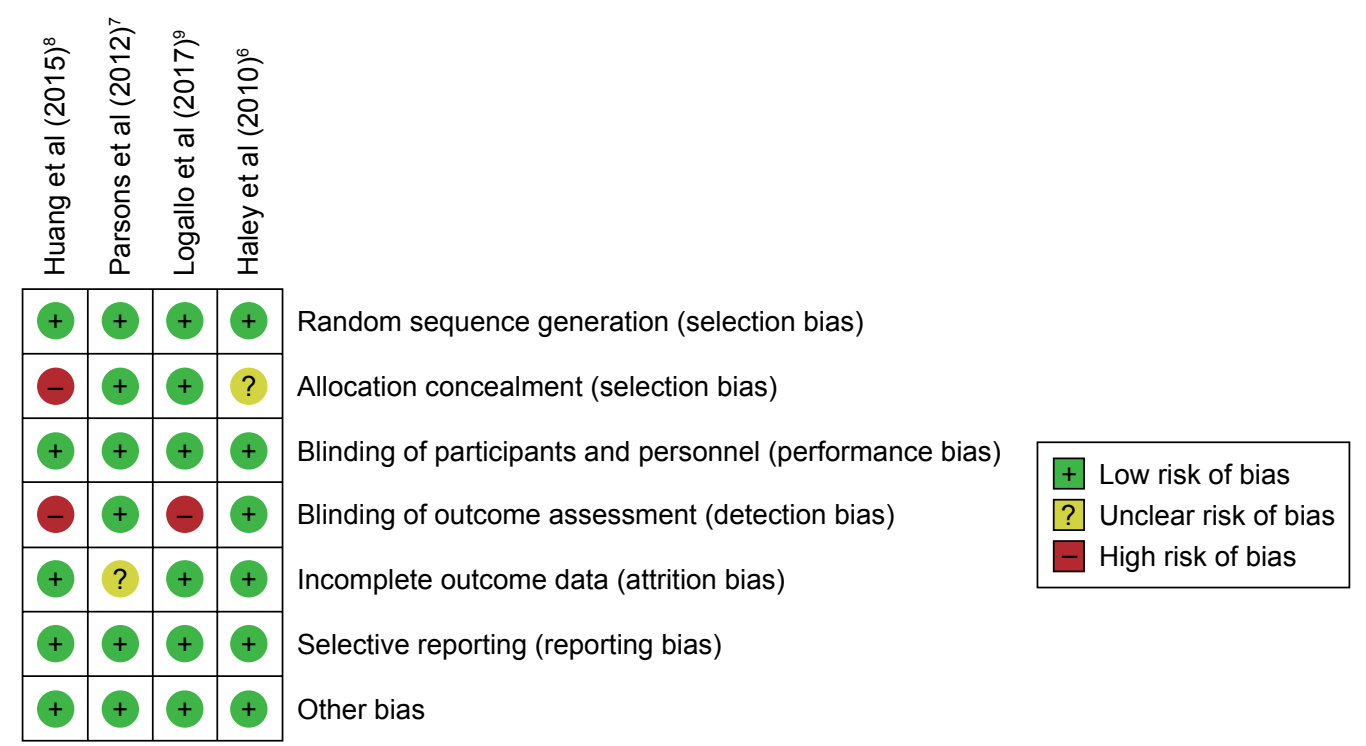

Figure 6 Risk of bias: a summary table for each risk of bias item for each study.

the latest protocol of clinical RCTs in which tenecteplase vs alteplase also included recanalization indicators. ${ }^{21}$ Therefore, in the further clinical randomized controlled study, the recanalization rate can be considered as an important evaluation index of treatment effectiveness.

This meta-analysis analyzed the safety of tenecteplase and alteplase including $\mathrm{sICH}$, any $\mathrm{ICH}$, dependence, and mortality. In the overall analysis and dose subgroup analysis, there was no statistical difference in the safety of the two drugs. However, the trend of a lower ICH risk was still found at the $0.25 \mathrm{mg} / \mathrm{kg}$ dose of tenecteplase than alteplase. Therefore, we conducted further subgroup analysis using different criteria for evaluation. We found that the risk of ICH was significantly lower when tenectplase was compared with alteplase in the high NIHSS scores at baseline of clinical trials. A higher NIHSS score at baseline means that AIS patients were in more serious condition. This may also mean that in patients with more severe AIS, the risk of ICH with tenecteplase was lower than that of alteplase. At the same time, RCTs of tenecteplase and alteplase can be considered for the inclusion of patients with high NIHSS scores to explore whether the risks of ICH are different in the future. A three-period RCT (NOR-TEST trial ${ }^{9}$ ) also came to the same conclusion that further trials are needed to establish the efficacy and safety in AIS patients with severe stroke and whether tenecteplase is noninferior to alteplase.

It is unclear whether the tenecteplase reaches the appropriate concentration. Our present meta-analysis showed that the $0.25 \mathrm{mg} / \mathrm{kg}$ dose of tenecteplase led to an increased early neurological improvement $(P<0.001)$ and a trend for lower risk of any $\mathrm{ICH}(P=0.076)$. However, the 0.1 and $0.4 \mathrm{mg} / \mathrm{kg}$ doses of tenecteplase compared to alteplase did not significantly improve early neurological improvement. The reason is probably that the NIHSS score at baseline of RCT (NOR-TEST trial) including $0.4 \mathrm{mg} / \mathrm{kg}$ dose of tenecteplase was low, so even though the recovery of patients was good, the early neurological improvement (NIHSS scores decease) is not significant. Then, did a high dose of tenecteplase cause a higher risk of ICH? The current study of high dose of tenecteplase $(0.4 \mathrm{mg} / \mathrm{kg}$ dose) did not increase the risk of ICH in patients. In addition, increasing the dose of tenecteplase may increase the chance of recanalization. Nevertheless, due to the lack of relevant data, it is impossible to draw a firm conclusion. The current evidence tends to support the use of $0.25 \mathrm{mg} / \mathrm{kg}$ of tenecteplase, which provided better early neurological improvement and less bleeding propensity than alteplase. Therefore, the latest protocol of RCT, the dose of tenecteplase is still $0.25 \mathrm{mg} / \mathrm{kg} .{ }^{21}$ As mentioned earlier, further clinical randomized controlled studies cannot ignore the patients of high NIHSS score at baseline with high-dose tenecteplase vs alteplase in clinical controlled trials.

Present meta-analysis still has several limitations that should be noted. First, we performed this analysis based on limited data. Only four published RCTs with 1,390 patients were pooled to test the efficacy and safety of tenecteplase for AIS with different doses. Second, different RCT studies lacked uniform research indicators such as different doses of 
tenecteplase and disease severity in patients in these trials. In particular, the NOR-TEST trial used high doses of tenecteplase and had a large sample size compared to other RCTs in relatively mild strokes. The data for all patients may be imbalanced and over-dominated by a single large trial with specific protocol conditions. Therefore, the NOR-TEST trial caused a certain degree of bias to the conclusions. However, we used different doses of subgroup analysis to reduce the bias. In addition, the NOR-TEST trial was a randomized, open-label, blinded endpoint trial from 13 centers, which is more better fit to the real situation. Third, only one RCT study was a Phase III clinical trial; hence, this meta-analysis lacked more comprehensive, multicenter, large-sample randomized controlled clinical trials. Finally, in NOR-TEST ${ }^{9}$ clinical study, the AIS patients were milder and more people were lost to follow up, which reduced the detection of outcome differences in intent-to-treat analysis.

\section{Conclusion}

The present meta-analysis indicated that tenecteplase provided better early neurological improvement than alteplase. The $0.25 \mathrm{mg} / \mathrm{kg}$ dose of tenecteplase subgroup especially showed better early neurological improvement and lower any ICH tendency than alteplase. In addition, in serious stroke at baseline subgroup, tenecteplase showed a lower risk of any $\mathrm{ICH}$. These data provide guarantees for further researches on tenecteplase in AIS.

\section{Acknowledgment}

This work was supported by the National Natural Science Foundation of China (no 81571115).

\section{Author contributions}

All authors made substantial contributions to conception and design, acquisition of data, or analysis and interpretation of data; took part in drafting the article or revising it critically for important intellectual content; gave final approval of the version to be published; and agree to be accountable for all aspects of the work.

\section{Disclosure}

The authors report no conflicts of interest in this work.

\section{References}

1. Powers WJ, Rabinstein AA, Ackerson T, et al. 2018 guidelines for the early management of patients with acute ischemic stroke: a guideline for healthcare professionals from the American Heart Association/American Stroke Association. Stroke. 2018;49(3):e46-e110.
2. Wang X, You S, Sato S, et al. Current status of intravenous tissue plasminogen activator dosage for acute ischaemic stroke: an updated systematic review. Stroke Vasc Neurol. 2018;3(1):28-33.

3. Correction to: efficacy and safety of a pharmaco-invasive strategy with half-dose alteplase versus primary angioplasty in ST-segmentelevation myocardial infarction: EARLY-MYO Trial (Early Routine Catheterization After Alteplase Fibrinolysis Versus Primary PCI in Acute ST-Segment-Elevation Myocardial Infarction). Circulation. 2018;137(7):e29.

4. Meurer WJ, Barth B, Abraham M, Hoffman JR, Vilke GM, DeMers G. Intravenous recombinant tissue plasminogen activator and ischemic stroke: focused update of 2010 clinical practice advisory from the American Academy of Emergency Medicine. J Emerg Med.2018;54(5): 723-730.

5. Lokeskrawee T, Muengtaweepongsa S, Patumanond J, et al. Prediction of symptomatic intracranial hemorrhage after intravenous thrombolysis in acute ischemic stroke: the symptomatic intracranial hemorrhage score. J Stroke Cerebrovasc Dis. 2017;26(11):2622-2629.

6. Haley EC Jr, Thompson JL, Grotta JC, et al. Phase IIB/III trial of tenecteplase in acute ischemic stroke: results of a prematurely terminated randomized clinical trial. Stroke. 2010;41(4):707-711.

7. Parsons M, Spratt N, Bivard A, et al. A randomized trial of tenecteplase versus alteplase for acute ischemic stroke. $N$ Engl J Med. 2012;366(12): 1099-1107.

8. Huang X, Cheripelli BK, Lloyd SM, et al. Alteplase versus tenecteplase for thrombolysis after ischaemic stroke (ATTEST): a phase 2, randomised, open-label, blinded endpoint study. Lancet Neurol. 2015; 14(4):368-376.

9. Logallo N, Novotny V, Assmus J, et al. Tenecteplase versus alteplase for management of acute ischaemic stroke (NOR-TEST): a phase 3, randomised, open-label, blinded endpoint trial. Lancet Neurol. 2017; 16(10):781-788.

10. Keyt BA, Paoni NF, Refino CJ, et al. A faster-acting and more potent form of tissue plasminogen activator. Proc Natl Acad Sci U S A. 1994; 91(9):3670-3674.

11. Benedict CR, Refino CJ, Keyt BA, et al. New variant of human tissue plasminogen activator (TPA) with enhanced efficacy and lower incidence of bleeding compared with recombinant human TPA. Circulation. 1995;92(10):3032-3040.

12. Huang X, MacIsaac R, Thompson JL, et al. Tenecteplase versus alteplase in stroke thrombolysis: an individual patient data metaanalysis of randomized controlled trials. Int J Stroke. 2016;11(5): 534-543.

13. Liberati A, Altman DG, Tetzlaff J, et al. The PRISMA statement for reporting systematic reviews and meta-analyses of studies that evaluate healthcare interventions: explanation and elaboration. BMJ. 2009; 339:b2700.

14. Kulkens S, Hacke W. Thrombolysis with alteplase for acute ischemic stroke: review of SITS-MOST and other phase IV studies. Expert Rev Neurother. 2007;7(7):783-788.

15. Haley EC Jr, Lyden PD, Johnston KC, Hemmen TM, Investigators TNKiS. A pilot dose-escalation safety study of tenecteplase in acute ischemic stroke. Stroke. 2005;36(3):607-612.

16. Haley EC Jr, Levy DE, Brott TG, et al. Urgent therapy for stroke. Part II. Pilot study of tissue plasminogen activator administered 91-180 minutes from onset. Stroke. 1992;23(5):641-645.

17. Brott TG, Haley EC Jr, Levy DE, et al. Urgent therapy for stroke. Part I. Pilot study of tissue plasminogen activator administered within 90 minutes. Stroke. 1992;23(5):632-640.

18. Hacke W, Albers G, Al-Rawi Y, et al. The Desmoteplase in Acute Ischemic Stroke Trial (DIAS): a phase II MRI-based 9-hour window acute stroke thrombolysis trial with intravenous desmoteplase. Stroke. 2005;36(1):66-73. 
19. Garcia-Pastor A, Diaz-Otero F, Funes-Molina C, et al. Tissue plasminogen activator for acute ischemic stroke: calculation of dose based on estimated patient weight can increase the risk of cerebral bleeding. J Thromb Thrombolysis. 2015;40(3):347-352.

20. Marshall RS. Progress in intravenous thrombolytic therapy for acute stroke. JAMA Neurol. 2015;72(8):928-934.
21. Campbell BC, Mitchell PJ, Churilov L, et al. Tenecteplase versus alteplase before endovascular thrombectomy (EXTEND-IA TNK): a multicenter, randomized, controlled study. Int J Stroke. 2018;13(3): $328-334$. 


\section{Supplementary materials}

A

Meta-analysis estimates, given named study is omitted

I Lower Cl limit O Estimate I Upper Cl limit

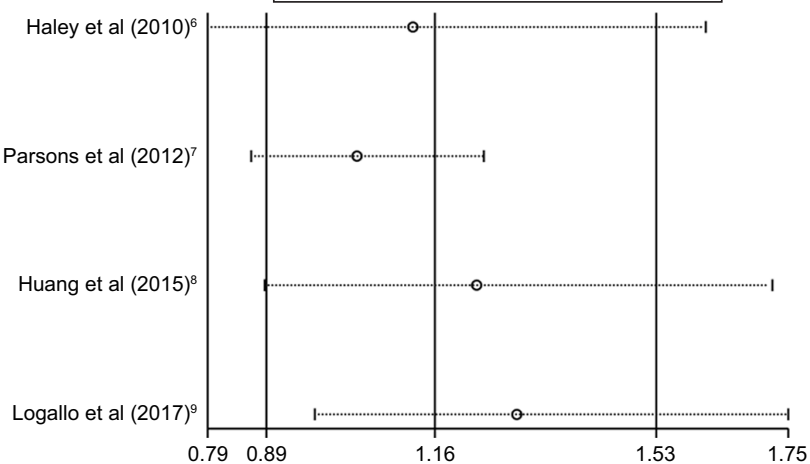

C

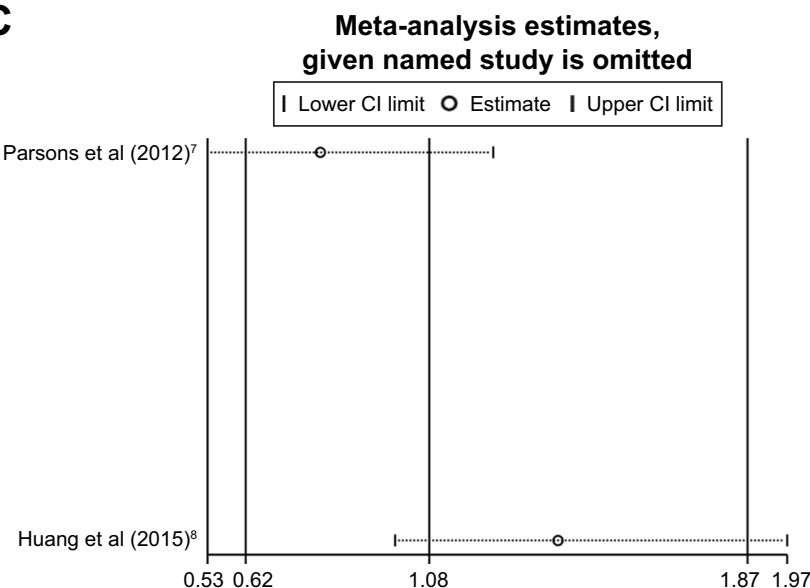

B

Meta-analysis estimates, given named study is omitted I Lower Cl limit $\mathrm{O}$ Estimate I Upper Cl limit

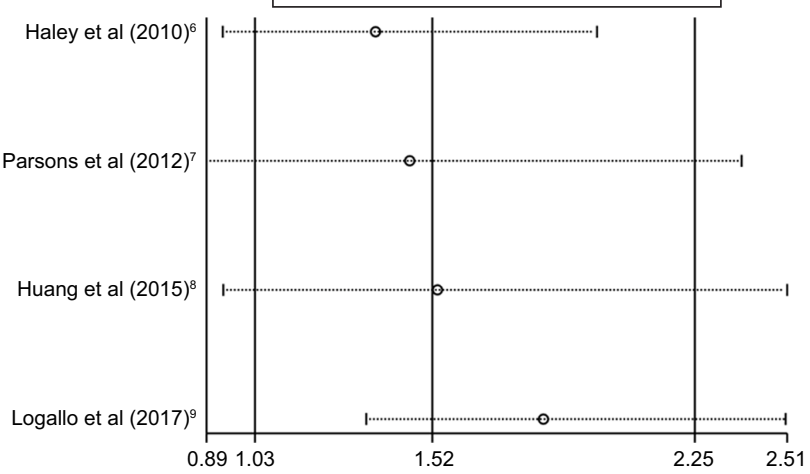

D

Meta-analysis estimates, given named study is omitted

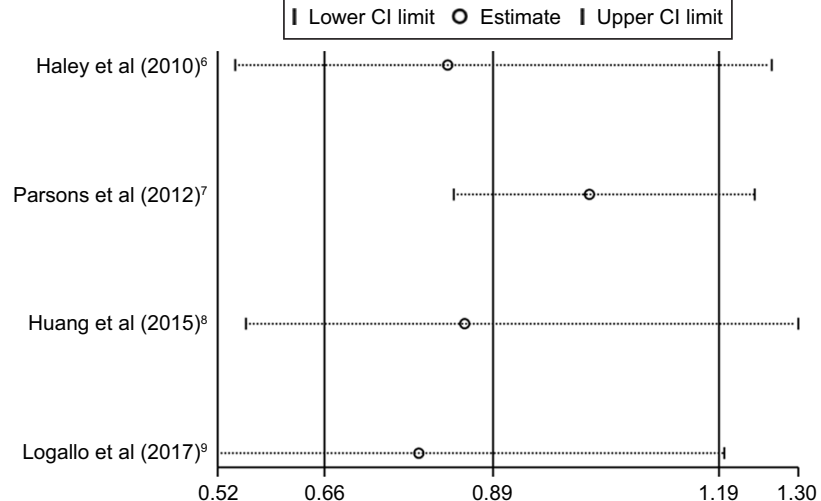

Figure SI The sensitivity analysis showed that all of the consolidated results were stable.

Notes: (A) A sensitivity analysis of good functional outcome from four RCTs. (B) A sensitivity analysis of early neurological improvement from four RCTs. (C) A sensitivity analysis of recanalization within $24 \mathrm{~h}$ from two RCTs. (D) A sensitivity analysis of dependence from four RCTs.

Abbreviations: $\mathrm{Cl}$, confidence interval; $\mathrm{RCTs}$, randomized controlled trials. 
A

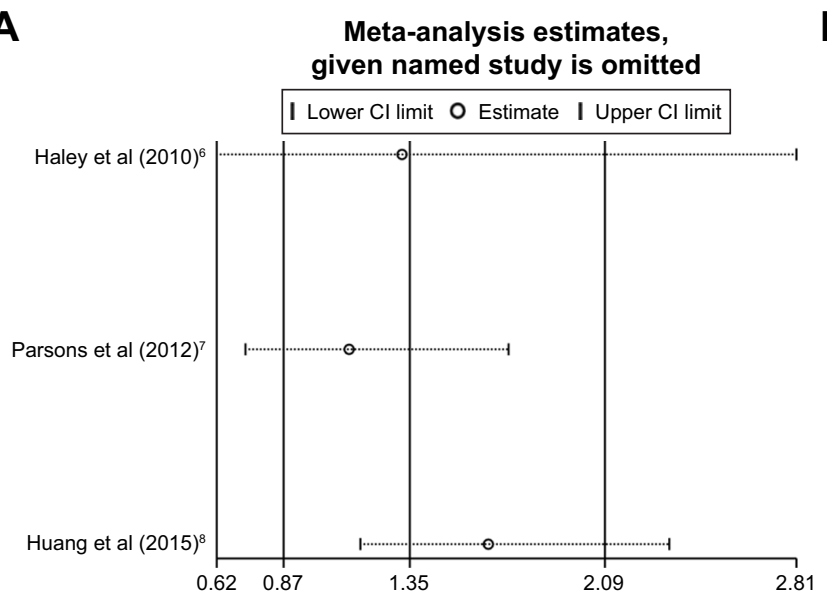

C

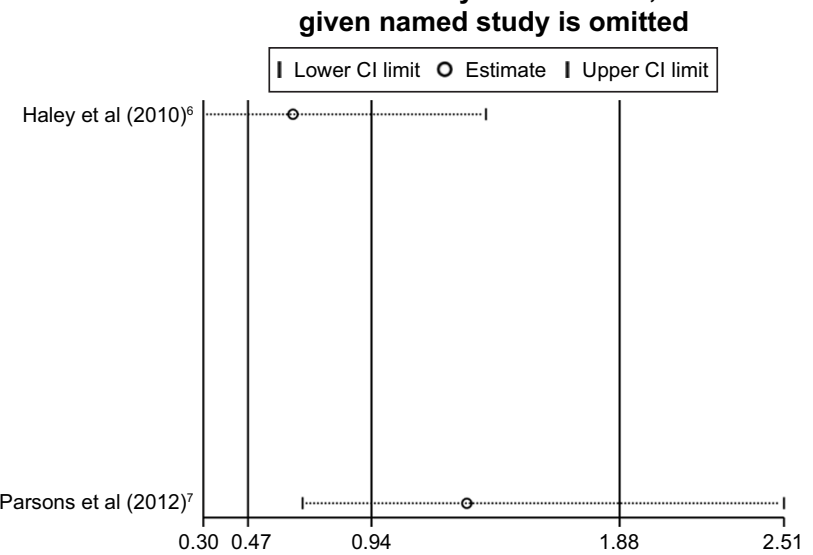

B

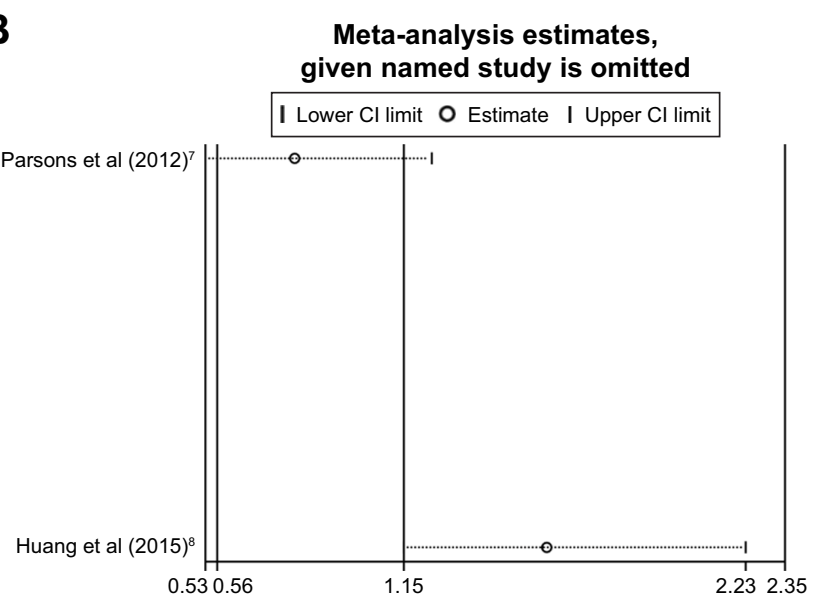

D

Meta-analysis estimates, given named study is omitted

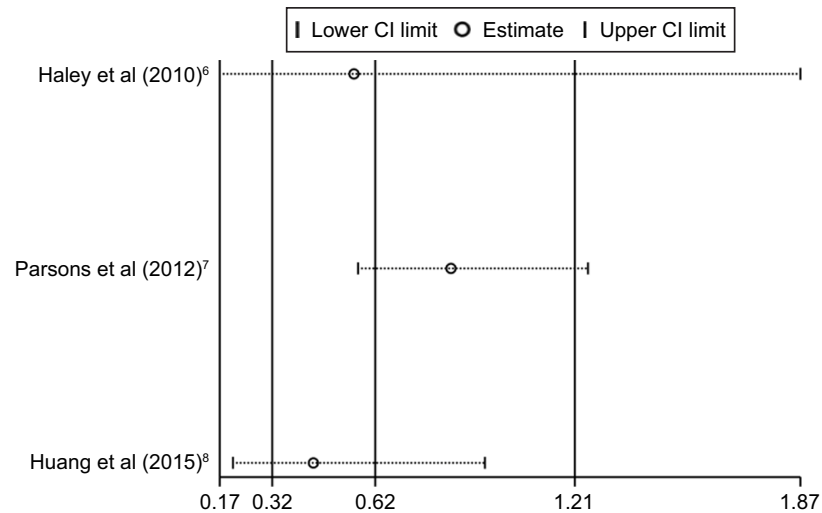

Figure S2 The sensitivity analysis showed that the different doses of tenecteplase subgroup results were stable.

Notes: (A) A sensitivity analysis of good functional outcome with $0.25 \mathrm{mg} / \mathrm{kg}$ subgroup from three RCTs. (B) A sensitivity analysis of recanalization with $0.25 \mathrm{mg} / \mathrm{kg}$ from two RCTs. (C) A sensitivity analysis of dependence with $0.1 \mathrm{mg} / \mathrm{kg}$ subgroup from two RCTs. (D) A sensitivity analysis of dependence with $0.25 \mathrm{mg} / \mathrm{kg}$ subgroup from three RCTs.

Abbreviations: $\mathrm{Cl}$, confidence interval; $\mathrm{RCT}$ s, randomized controlled trials.

\section{Publish your work in this journal}

Drug Design, Development and Therapy is an international, peerreviewed open-access journal that spans the spectrum of drug design and development through to clinical applications. Clinical outcomes, patient safety, and programs for the development and effective, safe, and sustained use of medicines are the features of the journal, which has also been accepted for indexing on PubMed Central. The manuscript management system is completely online and includes a very quick and fair peer-review system, which is all easy to use. Visit http://www.dovepress.com/testimonials.php to read real quotes from published authors. 